\title{
MANAGEMENT OF ANAL FISTULA
}

\author{
Dragoslav Mladenovic
}

\author{
St. Naum Ohridski University Clinic of Surgery, Skopje, Macedonia
}

\begin{abstract}
Anal fistula is a chronic condition that may present de novo or after an acute anorectal abscess. Management goal is to eradicate the fistula and prevent recurrence while maintaining continence.

Simple or low anal fistulas are best treated with a primary fistulotomy with excellent healing rates and functional outcomes. The management of complex anal fistulas is more difficult and controversial. No proved surgical procedure has gained acceptable as the gold standard yet. Over the last two decades, many sphincter-preserving procedures were introduced with the common goal of minimizing the injury to the anal sphincter and preserving the optimal function. Recently, a number of new techniques were developed and proposed such as ligation of intersphincteric fistula tract (LIFT); endorectal advancement flap (EAF); video-assisted anal fistula treatment (VAAFT); fistula tract laser closure (FiLAC); fibrin sealants and anal fistula plug (AFP), and adipose-derived stem cells (ASC). There are multiple techniques available for complex anal fistula repair. The best technique is not known yet, and the evidence available suffers from a lack of high-quality data and presents with very few large randomized studies. This review summarizes the management of anal fistulas and the current techniques available. It describes some new technologies, too. Scr Sci Med 2017;49(3):15-18
\end{abstract}

Keywords: anal fistula, surgical techniques, sphincter-sparing operations, fibrin sealants, adipose-derived stem cells

Address for correspondence:

Prof. Dragoslav P. Mladenovic

St. Naum Ohridski University Clinic of Surgery

Dame Gruev, Skopje 1000

Macedonia

e-mail: dragoslav.mladenivic@gradskahirurgija.org.mk

Received: April 10, 2017

Accepted: July 3, 2017

\section{INTRODUCTION}

Anal fistula is a chronic condition that may present de novo or after an acute anorectal abscess. It is characterized by chronic purulent drainage or cyclic pain associated with abscess formation followed by intermittent spontaneous decompression (1). Anal fistula prevalence is $1-2$ per 10000 of the population in European studies (2).

Perianal fistula management was documented by Hippocrates time in 400 B.C. as a part of the 'Cor- 
pus Hippocraticum' in a treatise entitled 'On fistulae'. A simple low fistula-in-ano is best treated with a primary fistulotomy, however, the approach to complex anal fistulas is more difficult, with higher rates of failure and functional disability. Many definitions exist for a complex anal fistula. In 2011, the Standards Practice Task Force for the American Society of Colon and Rectal Surgeons (ASCRS) defines complex fistulas as involvement of more than $30 \%$ of external sphincter or anterior fistulas in women, as well as recurrent fistulas in women, as well as those associated with preexisting fecal incontinence, inflammatory bowel disease, or radiation (3).

Treatment goals in an anal fistula are to eradicate sepsis, eliminate primary fistula opening, any associated tracts, secondary openings and to preserve the sphincters and the mechanism of continence $(4,5)$. Key principles for anal fistula management are described by the acronym SNAP, which stands for Sepsis, Nutrition, Anatomy and Procedure. Selection of the surgical procedure is the key to successful management (6).

This present article aims at providing the pragmatic overview on the new sphincter-preserving techniques proposed for the treatment of a complex fistula-in-ano.

\section{FIBRIN GLUE}

Fibrin glue is combination of fibrinogen, thrombin and calcium in a matrix. The fistula tract is filled with glue. Both internal and external fistula openings do not need to be closed (7). Using fibrin glue as a first line or besides other treatments is controversial during the last two decades. An overall fibrin glue fistula closure rate of $85 \%$ was achieved (8). The use of fibrin glue and other sealants fell out of the favour for the complex fistulas. However, the ASCRS practice parameters still list it as an acceptable approach to fistulas, giving it a grade of recommendation of $2 \mathrm{C}$ (3). Infection development is the most common complications after fibrin sealant use for fistula-in-ano.

\section{AFP}

The AFP technique was first described in 2004 and subsequently published in 2006 (9). The biological AFP is manufactured from porcine small intestine mucosa. AFP insertion is a sphincter-sparing procedure. The plug is pulled through the fistu- la track and secured in place of the internal opening, then trimmed of the external opening, which is left open for drainage (6).

According to H. Abcarian (2014), introduction for AFP use includes: i) transsphincteric fistula; ii) intersphinteric fistula; iii) extrosphincter fistula, and iv) anovaginal fistula.

AFP appears to be an acceptable approach to complex anal fistulas. However, postoperative failure is common and the patient needs proper and regular counseling.

\section{EAF}

The EAF involves mobilizing the partial thickness comprising the rectal mucosa or submucosa to the fistula tract which communicate with the bowel and cover the internal opening with disease-free anorectal wall. To ensure adequate blood supply, the base should be broader than the tip at least of 2:1 ratio (11). Modifications include curved incisions, rhomboid flaps, anorectal flaps with proximal advancement and closure or dissection of the remaining fistula track (6). The EAF is associated with mucosal ectropions or creation of a much larger defect than previously excised. For these reasons, an advancement flap from the outside of the anal canal is developed. This technique is known as a dermal advancement flap (DAF). Several different flap configurations are described including V-Y flaps, Y-V flaps, house flaps, S-flaps etc. (12). Overall, the functional outcomes and healing rates of the DAF are similar to that of the EAF. Therefore, it is an appropriate first-line therapy for complex anal fistula patients (11).

\section{LIFT}

The LIFT is a new promising sphincter-sparing procedure first described in 1993 (13). It gained popularity after its revision in 2007 (14). A skin incision is made between the internal and external anal sphincter. After the intersphinteric tract is identified and dissected, it is ligated closely to the internal sphincter, and external opening debridement is carried out. Finally, the incision wound is loosely closed (11). According to a recent meta-analysis of 24 original articles, LIFT procedure has the advantages of anal sphincter preservation, minimal tissue injury, short healing time with no additional cost (15). Besides it is relatively easy to perform. If a failure occurs, the procedure can be readily repeated. A recent 
modification known as bioLIFT is a variation of the LIFT technique in which a bioprosthesis is placed in to reinforce fistula tract closure. When compared to the LIFT, the bioLIFT technique presents with five potential disadvantages. First, it requires a more extensive dissection in the intersphinteric space because the bioprosthesis must overlap the closure of the fistula tract by at last $102 \mathrm{~cm}$ in all directions. The second disadvantage is the relatively high cost of the bioprosthetic materials.

\section{ASCs}

Application of autologous ASCs represents a novel approach for enhancing the regeneration of damaged tissues in an environment that is particularly unfavourable for wound healing. Following fistula tract curettage and internal opening suture, ASCs solution is injected into the walls of the fistula. The tract is subsequently sealed with fibrin glue. Up-to-date, it is difficult to make a firm judgement on this technique because of limited data available. There are no reports on the ASC long-term effects yet (16).

\section{FiLaC}

One of the newest technologies on the market is the use of a laser to ablate the fistula tract, using a newly invented radial emitting laser probe (Fi$\left.\mathrm{LaC}^{\mathrm{m}}\right)$ initially described in 2011 (17). The FiLaC is a sphincter- saving technique which destroys the fistula epithelium and simultaneously obliterates the remaining fistula tract. It requires expensive equipment, particularly if compared to other sphincter-saving techniques.

\section{VAAFT}

VAAFT is a novel minimally invasive and sphincter-saving technique for treating complex fistulas developed by P. Meinero and L. Mori in 2006 (18). It is performed with a kit which includes a fistuloscope, an obturator, an unipolar electrode, an endobrush and $0,5 \mathrm{~mL}$ of synthetic cyanoacrylate glue. The aim is to destroy the fistula tract from the inside, heal it and close the internal opening. The fistula wall is cauterized and all wasted material is eliminated into the rectum through the internal opening. Finally, the internal opening is sutured by semicircular or linear stapler. In order to reinforce the staple line, $0,5 \mathrm{~mL}$ of synthetic cyanoacrylate glue can be applied. VAAFT disadvantages include the excessive fistula dilatation in order to insert the fistuloscope, the substantial internal opening damage by the electrode which is higher than that of the laser, the high kit and stapler costs, and the long operative time. Therefore, improvements of the technique and further studies are required (5).

\section{CONCLUSION}

There are numerous techniques for complex anal fistula repair available, however, the best technique is not known yet. The technique of choice will depend on patients' selection, control of sepsis, surgeon's preference and familiarity with different techniques. The advancement flap still remains the gold standard, but LIFT may potentially play a fundamental role in the future.

\section{REFERENCES}

1. Whiteford MH, Kilkenny J 3rd, Hyman N, Buie WD, Cohen J, Orsay C, et al.; Standards Practice Task Force; American Society of Colon and Rectal Surgeons. Practice parameters for the treatment of perianal abscess and fistula-in-ano (revised). Dis Colon Rectum. 2005;48(7):1337-42. doi: 10.1007/ s10350-005-0055-3.

2. Zanotti C, Martinez-Puente C, Pascual I, Pascual M, Herreros D, García-Olmo D. An assessment of the incidence of fistula-in-ano in four countries of the European Union. Int J Colorectal Dis. 2007;22(12):1459-62. doi: 10.1007/ s00384-007-0334-7.

3. Steele SR, Kumar R, Feingold DL, Rafferty JL, Buie WD; Standards Practice Task Force of the American Society of Colon and Rectal Surgeons. Practice parameters for the management of perianal abscess and fistula-in-ano. Dis Colon Rectum. 2011;54(12):1465-74. doi: 10.1097/ DCR.0b013e31823122b3.

4. Lim SW. Surgery in an intersphinteric fistula. J Korean Soc Coloproctol. 2009;25(6):365-71. doi: org/10.3393/jksc.2009.25.6.365.

5. Limura E, Giordano P. Modern management of anal fistulas. World J Gastroenterol. 2015;21(1):1220. doi: 10.3748/wjg.v21.i1.12.

6. Simpson JA, Bauerjea A Scholefield JH. Management of anal fistulas. BMJ. 2012;345:e6705. doi: 10.1136/bmj.e6705. 
7. Cintron SM. New techniques in the treatment of common perianal diseases: stapled hemorrhoidectomy, botulinum toxin, and fibrin sealant. Surg Clin North Am. 2016;84(4):937-67. doi: 10.1016/j. suc.2006.06.009.

8. Sentovich SM. Fibrin glue for all anal fistulas. J Gastrointest Surg. 2001;5(2):158-61.

9. Johnson EK, Gaw JU, Armstrong DN. Efficacy of anal fistula plug vs. fibrin glue in closure of anorectal fistulas. Dis Colon Rectum. 2006;49(3):371-6. doi: 10.1007/s10350-005-0288-1.

10. Abcarian $\mathrm{H}$. Anal fistula: principles and management. New York: Springer; 2014.

11. Bubbers EJ, Cologne KG. Management of complex anal fistulas. Clin Colon Rectal Surg. 2016;29(1):439. doi: 10.1055/s-0035-1570392.

12. Farid M, Youssef M, El Nakeeb A, Fikry A, El Awady S, Morshed M. Comparative study of the house advancement flap, rhomboid flap, and Y-V anoplasty in treatment of anal stenosis: a prospective randomized study. Dis Colon Rectum. 2010;53(5):790-7. doi: 10.1007/ DCR.0b013e3181d3205a.

13. Matos D, Lunniss PJ, Phillips RK. Total sphincter conservation in big fistulas in ano: results of a new approach. Br J Surg. 1993;80(6):802-4.

14. Rojanasakul A, Pattanaarun J, Sahakitrungruang C, Tantiphlachiva K. Total anal sphincter saving technique for fistula-in-ano; the ligation of intersphincteric fistula tract. J Med Assoc Thai. 2007;90(3):581-6.

15. Hong KD, Kang S, Kalaskar S, Wexner SD. Ligation of intersphincteric fistula tract (LIFT) to treat anal fistula: systematic review and meta-analysis. Tech Coloproctol. 2014;18(8):685-91. doi: 10.1007/ s10151-014-1183-3.

16. Song KH. New techniques for treating an anal fistula. J Korean Soc Coloproctol. 2012;28(1): 7-12. doi: 10.3393/jksc.2012.28.1.7.

17. Wilhelm A. A new technique for sphincter-preserving anal fistula repair using a novel radial emitting laser probe. Tech Coloproctol. 2011 Dec;15(4):4459. doi: 10.1007/s10151-011-0726-0.18.

18. Meinero P, Mori L. Video-assisted anal fistula treatment (VAAFT): a novel sphincter-saving procedure for treating complex anal fistulas. Tech Coloproctol. 2011;15(4):417-22. doi: 10.1007/ s10151-011-0769-2. 